\title{
Social workers in China: Professional identity in the making
}

This article examines how frontline Chinese social workers navigate between several professional ideals and mobilize different values through their everyday practices. Often starting the work without formal qualifications, their professional identity evolves through a combination of on-the-job training and supervision, studying national textbooks for qualifying exams, and exposure to international ideas about social work. Discussions about social work in China have typically centred on the applicability of Western models and the political dynamics between different stakeholders. The current study extends these discussions by taking a view 'from below' on how different - and at times conflicting - sets of professional standards are experienced by social workers and how they make decisions within this context. The analysis is based on ethnographic fieldwork at a social service centre in Guangzhou that caters to both foreign and local populations. China has trained more than a million individuals in social work, and 312,000 people are employed as social workers (Ministry of Civil Affairs, 2018). This article seeks to illuminate the qualitative implications of this globally unprecedented quantitative expansion.

Keywords: China, indigenisation, professional identity, qualitative methods, social policy.

\section{Introduction}

Social work in China has expanded at a globally unprecedented scale. More than one million individuals have received social work training over the past decade, and 312,000 people were employed as social workers at the end of 2017 (Ministry of Civil Affairs, 2018). The philosophy behind this rapid expansion has been summed up by Chinese scholars with the phrase xian you, hou hao - "quantity first, then quality" (Ma et al., 2015). Concurrently, with the push for quantitative expansion, initiatives to promote the professionalization of social work, such as standardized national curricula and qualifying exams, have been implemented. National professional accreditation examinations in social work, based on state-approved textbooks, are now organized yearly (Ministry of Human Resources/Ministry of Civil Affairs 2006; Wang et al., 2015). Social work in China, which was primarily the subject of academic discourse prior to these initiatives, is now an emerging field of practice (Gao and Yan, 2015).

This article investigates how the processes of professionalization and indigenization of Chinese social work is experienced by social workers. The analysis takes a perspective "from 
Postprint. Reference: Niu, D \& Haugen, HØ (2019) The British Journal of Social Work 49 (7), 19321949. Copy of the published article can be obtained by emailing h.o.haugen[AT]ikos.uio.no

below" by examining how different values were mobilized through everyday practices at a social service centre in the city of Guangzhou, South China, a so-called Integrated Family Service Centre (for a discussion of this organizational structure, see Chan and Lei, 2017). The analysis supports the assertion that the professional identity of social workers often comes across as much through the choices they make in their daily practice as by how they selfidentify (Witkin, 1999). Social workers everywhere must negotiate contradictive objectives and considerations, but the rapid developments in this field in China have made such contradictions particularly pronounced.

The rest of this article is organized as follows. First, we provide a brief overview of research on the formation of professional identity in social work. Second, we discuss the status of the profession of social work in China today. Third, we examine the role of ethnography in social work research and present the methodological approach adopted in our study. The remainder of the article is devoted to an analysis of how the professional identity of a small group of social workers evolved over a two-year period, during which they were exposed to different sources of professional values and expectations. At first, they navigated these demands with relative ease. However, as the social service centre they worked at was placed under increasing public scrutiny and the political context changed, they found it increasingly difficult to reconcile the role assigned to them by administrators and politicians with the professional identity they came to adopt. In the conclusion, we argue that the professional constraints experienced by the social workers participating in this study are relevant for understanding the challenges social workers in China currently face.

\section{The professional identity of social workers}

Professional identity develops through professional socialization, whereby individuals acquire knowledge and skills specific to their field of work and internalize the values and norms of the group (Adams, 2006:57). Studies of social work students and professionals conceptualize professional identity as an ongoing process of "becoming" rather than a fixed state of being (Scanlon, 2011). Miehls and Moffatt (2000) argue that the open-endedness of identity formation can help promote professionalism that is sensitive to the experience of others. They endorse social work education that encourages students to "be reconstituted in the presence of others" rather than controlling anxiety by the mastery of a certain theory (ibid.:346).

Literature on social work education highlights the role of supervision as a source of regulation and guidance in professional identity formation (Ben Shlomo et al, 2012). Studies of the day- 
Postprint. Reference: Niu, D \& Haugen, HØ (2019) The British Journal of Social Work 49 (7), 19321949. Copy of the published article can be obtained by emailing h.o.haugen[AT]ikos.uio.no

to-day practice of social work emphasize the role of peers in consolidating professional identity (Scholar et al., 2014).

The professional identity of individuals is developed within specific institutional contexts. At a global level, the International Federation of Social Workers (IFSW) has reconciled divergent practices and methodologies of social work through a core definition of the social work profession (Hare, 2004). While national associations of social work around the world have adopted this definition, professional identities have developed differently depending on policy contexts and welfare regimes (Campanini et al., 2012). The identity of social workers in many Western countries has been affected by a shift in responsibility for service delivery towards non-government providers, with a concomitant focus on quantitative targets and weakened commitment to professional development (Healy \& Meagher 2004). Some of these trends also manifest in social work in China, to which we now turn.

\section{Social work in China}

Four decades of economic reforms in China have improved living standards across the country. However, the reforms also dismantled old systems for meeting social welfare needs and created wealth gaps that are a source of social tension. The overall rationale for bolstering social work in China has been to address these challenges (Leung et al., 2012). A 2006 decision by the Chinese Communist Party reads "To strengthen the Party's leadership to construct a socialist harmonious (hexie) society, $[\ldots]$ there is an urgent need to create an effectively organized team of highly qualified social workers" (CCPCC, 2006: our translation). The role of social work in creating a harmonious society is to mitigate the marginalization of less advantaged groups (Gao and Yan, 2015:94). Massive resources have been invested in social work as part of a more general strategy for community development as a means to achieve social harmony (Xu, 2008:637). Community, in this context, is a spatially delineated area where institutions provide welfare services to address the inhabitants' needs.

Chinese policy makers, academics, and practitioners have looked to Western countries for knowledge and methods for developing social work in China and sought to modify foreign ideas and practices to fit the national context (Yan and Tsang, 2008). However, political and academic actors diverged in their views of how social work practices from other countries ought to be adapted: Chinese policy discourses employed the term "social work with Chinese characteristics," while scholars tend to prefer the concept of "indigenization," which is employed in international scholarship (Yan and Cheng, 2009). The rich academic debate about the indigenization of social work in China highlights the heterogeneity of Western 
Postprint. Reference: Niu, D \& Haugen, HØ (2019) The British Journal of Social Work 49 (7), 19321949. Copy of the published article can be obtained by emailing h.o.haugen[AT]ikos.uio.no

social work systems as well as diverse social work ideals and practices within China (Bai, 2014; Gray, 2010). The Chinese heterogeneity results in part from the central government's policy of letting local authorities experiment with different approaches for delivering social services and defining the mandate of social workers (Gao and Yan, 2015). Furthermore, local governments outsource service delivery to non-governmental organizations (NGOs), and the management capacity of government bureaucrats as well as the aptitude of the NGOs bidding for contracts vary greatly (Chan and Lei, 2017).

Tensions between the two goals of promoting individual welfare and furthering a harmonious society are rarely made explicit in Chinese policy documents, textbooks, and professional guidelines. For example, a national textbook for junior social workers devotes a full chapter to "Social work values and professional ethics" (Wang et al., 2015:20-35), yet provides very vague guidance for interaction with clients. No case studies in the chapter guide students in how to deal with conflicting ethical principles in practice. The textbook stresses the importance of treating clients politely and truthfully, but the overarching aim of building a harmonious society takes precedence over such principles (ibid.:24). By not articulating how conflicting principles can give rise to practical dilemmas, social work academics and policy makers insulate themselves from political scrutiny and risk (Leung and Tam, 2015).

The relationship between macro-level developments in Chinese social work and the values held by individuals has become the topic of some scholarly attention (Bai, 2014). One qualitative survey concluded that social work graduate students mostly emphasized their discipline's responsibility to promote a harmonious society, although some also highlight the advocacy role of social workers (Yan and Cheng, 2009). Another study, conducted through qualitative interviews with practicing social workers, indicates that empathy is regarded as a key professional value among those who have received formal training in social work (Liu et al., 2012). A quantitative survey among both students and practitioners showed that they were committed to social work values as defined by the United States Association of Social Workers, including respect for basic individual rights and commitment to social advocacy, albeit to a lower degree than their Western counterparts (Zhao et al., 2017).

Social work as a professional field has low status in China. Along with poor salaries, heavy workloads, and weak professional guidance, the low public recognition has been put forward as an explanation for job dissatisfaction and high turnover rates in the sector (Gao and Yan, 2015; Jiang et al., 2017, Liu 2016). Furthermore, social work institutions are often poorly linked with other public service providers, resulting in ineffective help to clients and consequent disillusionment among social workers (Liu, 2016). In some contexts, social 
Postprint. Reference: Niu, D \& Haugen, HØ (2019) The British Journal of Social Work 49 (7), 19321949. Copy of the published article can be obtained by emailing h.o.haugen[AT]ikos.uio.no

workers have also lamented that their role in monitoring, or even "informally policing", clients is stronger than their means to alleviate the problems of people in need (Peng, 2010:57). The case discussed in this article suggests that contradicting professional demands further contribute to the problem of retaining social work professionals in China.

\section{Ethnographic approaches to social work}

Ethnographic methods have been argued to match social work in distinct ways (Archer, 2009). Social workers use observation, probes, and interviews to gauge how clients experience their own situations (ibid.). Similarly, researchers employ ethnographic methods to observe a part of society from the perspective of the subjects under study and provide descriptions to account for the system of meanings of social groups while relating them to wider contexts. Both social workers and ethnographers need to "theorize the particular in context" (Floersch et al., 2014:4); that is, to use theory to inform their analyses of specific situations.

Social work scholars initially embraced ethnography mainly as a method for developing better services for marginalized groups (Thornton and Garrett, 1995). The ethnographic lens was subsequently turned inwards to study the performance of social work (Ferguson, 2016). Ethnography provides social workers with a vantage point outside of their own cultural contexts, from which they may critically reflect on practices and policies (Haight et al., 2014). Some scholars have adopted a full membership role in the societies they studied and employed the method of auto-ethnography (White, 2001). One of the first social work researchers to analyse the profession from the inside through long-term participant observation was de Montigny (1995), a social worker who compellingly records how people in his profession order the world in ways that enable them to act but simultaneously disavow the complexity in their clients' lives.

Chinese social work scholars have employed ethnographic methods to a lesser extent than their Western counterparts. The most notable exception is scholarship on social work with ethnic minorities in China, where researchers have promoted ethnographic methods both in rural, minority-dominated areas and among non-Han internal migrants (Wang, 2014). Cultural sensitivity and cross-cultural competence are emphasized as important skills for social workers who practice among ethnic minority groups (Zhao and Yao, 2015:32). Some ethnic minority studies in China have been conducted with the explicit aim of providing information for the local governance of ethnic minorities (minzu gongzuo) (Li, 2009). 
Postprint. Reference: Niu, D \& Haugen, HØ (2019) The British Journal of Social Work 49 (7), 19321949. Copy of the published article can be obtained by emailing h.o.haugen[AT]ikos.uio.no

\section{Ethnographic methodology in the present study}

The analysis in this article is based on ethnographic fieldwork at a social service centre in Guangzhou. The data collection aimed to understand tensions in Chinese social work from the perspective of social workers. Author A was employed by the social service centre under study, whereas Author B carried out fieldwork among foreigners in the neighbourhood that the centre served. A long data collection period enabled us to capture transformations in the social workers' professional identity in response to external events, and identify specific instances of conflicts between various social work ideals in the social workers' daily practice.

The pseudonyms "Lotus" and "Huayuan" have been applied to the social service centre and the sub-district it is located within, respectively. Clients are fully anonymized, and the social workers (apart from Author A) are referred to by pseudonyms. However, the fieldwork site and social workers may be identifiable for readers who are familiar with the local context. The rich accounts created through ethnographic research of social work give rise to ethical challenges and calls for a careful consideration of how to report research (Burke, 2007). In addition to ensuring informed consent, we have consulted with the social workers who participated in the study during the drafting of this manuscript. Formal systems for ethical approval of ethnographic research have not yet been set up in China, despite calls from anthropologists to institutionalize ethical reviews (Sun 2013).

The Lotus centre provided services for families, the elderly, youth, and foreigners. Three full-time employees - Mary, Sky, and Author A —, along with a large number of mainly French language student volunteers, were hired to serve the latter group of clients. A local NGO had won the bid for government funding to operate a social service centre in the district of Huayuan. The NGO-run centre served the district's 100,000 residents, of which about 2,300 were foreign-born. The large foreign client group set the social service centre apart from most other Chinese social work institutions. These foreigners were mostly from non-Western countries, and exceptionally diverse in terms of age, gender, financial situation, immigration status, and nationality. The provision of social work to foreigners was launched during the fieldwork period. Due to the trial and error involved in setting up services from scratch and the vulnerability of parts of the client population, the social service provision for foreigners is a "critical case" — one that is particularly dense with information that helps highlight a general phenomenon (Flyvbjerg, 2006): the professional identity of social workers in China.

Author A was a frontline social worker in the Lotus centre from June 2013 to June 2015, serving as a full-time employee for the first 18 months. A non-native to Guangzhou, he 
Postprint. Reference: Niu, D \& Haugen, HØ (2019) The British Journal of Social Work 49 (7), 19321949. Copy of the published article can be obtained by emailing h.o.haugen[AT]ikos.uio.no

communicated with social workers, managers, and clients in Mandarin Chinese and English. He was a $\mathrm{PhD}$ student in ethnology at the time of the fieldwork, and he was employed at the Lotus centre on a standard employment contract. During the fieldwork period, he acquired certification as a national junior social worker. By becoming a social worker, he aligned his perspective with the social workers who became his research participants, thus actively working to take an insider view of social work. Author A's employer, colleagues, and clients at the Lotus centre were aware that he collected data for research, and informed consent was solicited when viable. Data from clients who had not actively consented to participating in the research has not been used in this article.

Author B undertook ethnographic fieldwork among West Africans in Guangzhou for a total of 16 months between 2009 and 2016, working in Mandarin Chinese, English, and French. As a European resident of Huayuan during these fieldwork periods, she was subject to the same control measures as other foreigners in the district. However, with a local university affiliation, residence permit, and knowledge of Chinese, her status was more secure than that of most other foreign residents in Huayuan. She was introduced to Lotus in February 2014, where she and her family members occasionally attended activities during the subsequent 11 months.

The knowledge produced through our fieldwork is necessarily influenced by how we are situated. Feminist critiques of objectivist research have encouraged researchers to reflect upon their own positions and write these accounts into their research practice (McDowell, 1992). While Author A was a social worker and Author B a member of the target group of Lotus' work, both were more privileged than these descriptions imply: Author A as a doctoral researcher with a range of career opportunities inside and beyond social work, and Author B as a financially secure documented immigrant. While we aspired to reflect upon how our positionality affected our relations and interpretations, we also recognize that we can never fully grasp the significance of our situatedness (cf. Rose, 1997:319).

\section{Professional identity in the making}

Approximately half the Lotus centre's 20 employees had no prior training in social work. Their identity as social workers emerged and evolved through meetings with clients and other social workers. The management encouraged them to take the junior and intermediate social work exams, which would formalize their competence. They were exposed to different, and partially conflicting, professional ideals and values through practical social work, social work textbooks, study trips to Hong Kong, and professional guidance from local and Hong Kong 
Postprint. Reference: Niu, D \& Haugen, HØ (2019) The British Journal of Social Work 49 (7), 19321949. Copy of the published article can be obtained by emailing h.o.haugen[AT]ikos.uio.no

supervisors. This pluralism, as the following discussion will illustrate, was variously experienced as paralyzing and as a source of autonomy.

The professional identity of the social workers who worked with foreigners changed over time as they faced dilemmas that forced them to choose between following established casework procedures and protecting the privacy and safety of their clients. They were eventually unable to reconcile the ideals they had adopted for social work with the expectations placed upon them by their superiors. Social work with foreigners was a highly politicized issue, and as pioneers in this work, Mary, Sky, and Author A had few role models and procedures to use as reference points when carrying out their duties. They adopted an iterative approach to deal with inconsistencies and problems as they became aware of them.

\section{Creating a harmonious society through social work}

"What is social work?" Author A asked his colleagues on his first day as an employee at the Lotus centre. An advertisement for volunteer teachers at the Lotus centre had provided him with an entry point to the field. After some weeks as a volunteer, he got a job as a full-time social worker, for which no prior experience or formal qualifications were required. The two other young people who provided social services for foreigners had no more experience than him when they first started. Sky who had been at the centre for almost a year, shared his understanding of the field. "Social work is organizing events," he explained. In fact, the Lotus centre had committed to organizing a certain number of events when they bid for funding from the local government. The centre's Chinese language classes were popular among clients from a wide range of African countries as well as some people from Eastern Europe, South Asia, and the Middle East, and were used as a means to establish contact with potential clients. A week after Author A started working at Lotus, he, Mary, and Sky set out to visit African residents at the request of their supervisor, who believed this group to be most in need of social services. The community police had provided Lotus with a list of names and addresses for foreigners in Huayuan. The three social workers brought their notebooks and pens and went knocking on doors.

Social service centres and street-level police officers are required to cooperate to keep the local community "harmonious". The police had their own ideas of the role of social work in such cooperation. On one hot July afternoon, as the social workers walked from door to door, the local police unit stopped them and made a request. "When you go inside [the apartments of foreigners from Africa], you should tell them to behave according to Chinese culture. They don't seem to educate their children!" the head officer said. "The children are 
Postprint. Reference: Niu, D \& Haugen, HØ (2019) The British Journal of Social Work 49 (7), 19321949. Copy of the published article can be obtained by emailing h.o.haugen[AT]ikos.uio.no

noisy, they fight, and they don't pay attention to their hygiene. They don't like to wear shoes or wash their hands." The social workers recalled that the request made them uncomfortable, not so much due to the derogatory descriptions as because they thought giving parenting advice was beyond their mandate. The police requested them to capitalize on the trust bestowed upon social workers to reduce friction between African and Chinese residents, and the three of them hesitated to take on the task. "We are supposed to organize events. Going into people's apartments to tell them how to educate their children is not our responsibility," they said to each other after the meeting. However, they found themselves unable to push back against the police request, in part because they had no well-defined notion of social work through which they could make their case.

Clients also challenged Mary, Sky, and Author A to define their professional identity. During a house visit, for example, a West African man questioned their status. "Why are you here - to check visas?" he said after they had introduced themselves. "No, we are social workers in the local community centre," they replied, and introduced the Chinese language classes the service centre offered. "In other countries, social workers help with housing, jobs, and health care. But you Chinese social workers don't do any of these things!" the man argued. "The biggest problem Africans in China face is maintaining a valid visa. Why don't you social workers start helping us solve this problem?" Many of the foreigners in Huayuan already held certain notions of social work based on their experiences in their home country or as migrants in Europe. The social workers smiled sheepishly at each other when confronted by the man, at a loss for words. "We [the social workers] didn't feel we had a purpose either," Author A recalled, as they lacked resources to create any substantial improvements in their clients' lives.

All social workers at Lotus took extensive notes about their clients. Case files and reports provided the basis for the centre's performance evaluation and renewed funding. The notes were often taken without the clients' knowledge or consent, a clear breach of the professional code of conduct issued by the International Federation of Social Workers (IFSW) (2012). The social workers who provided services to foreigners were not acquainted with the IFSW code of conduct, and did not reflect upon the ethical implications of this activity. Rather, they were determined to ensure that the centre got a favourable performance review. Their supervisor, who was in charge of their professional development, was also the leader of the NGO that was contracted to run the centre. Her communication with the employees of Lotus was focused on the importance of achieving measurable results. The emphasis on quantitative targets and results was not particular to how Lotus was managed, but rather a 
Postprint. Reference: Niu, D \& Haugen, HØ (2019) The British Journal of Social Work 49 (7), 19321949. Copy of the published article can be obtained by emailing h.o.haugen[AT]ikos.uio.no

result of the model that governed the relationship between the local government and social work contractors in Guangzhou in general (Chan and Lei, 2017:8). Ethical principles were not a subject of discussion between the supervisor and social workers at Lotus. While they nominally had assumed an identity as social workers, they had few tools for pondering the professional values that this title entailed.

\section{Providing services or managing foreigners?}

The idea of providing social services for foreigners in Guangzhou was launched in 2009. The city's policies toward foreign residents had focused solely on ensuring that laws and regulations were followed. This changed after Politburo Standing Committee member Zhou Yongkang visited Guangzhou in connection with the sixtieth anniversary of the People's Republic of China in 2009 and specifically requested a stop in the Huayuan district because of its large population of foreigners. Huayuan prepared African community leaders for the meeting. One of them was Ike, a Nigerian married to a Chinese woman, who conversed with Secretary Zhou with ease. Ike had only good things to say about living in China. At the end of their meeting, Zhou promised to look into how Guangzhou could provide more services to foreigner residents (Xu and Yue, 2009).

At the time, Guangzhou planned to strengthen social work. City officials looked to Hong Kong and Singapore for examples to emulate (Shu, 2009; Yan, 2010) and arrived at a model wherein it purchased sets of different services from independent organizations. The NGO that ran the Lotus centre had gained a strategic advantage over its competitors by including a section about foreigners in its proposal. The local government in Huayuan was compelled to follow up on Secretary Zhou's recommendations, and the proposed Lotus centre offered the means to do so.

In addressing potential clients, Mary, Sky, and Author A employed a terminology and approach associated with Chinese foreign policy discourse rather than international standards for social work. The IFSW (2012) code of ethics dictates that social workers should recognize "the boundaries between personal and professional life." However, this principle is not expounded in Chinese social work textbooks, one of which instructs social workers to "establish a mutual relationship of trust" with potential clients in order to prepare the ground for providing professional services (Wang et al., 2015:24). The social workers regarded friendships as a step on the way toward establishing client-social worker relationships. "Make friends with them first," Mary and Sky advised Author A when he asked them how he should approach clients. Beijing tends to describes relations between China and developing countries 
Postprint. Reference: Niu, D \& Haugen, HØ (2019) The British Journal of Social Work 49 (7), 19321949. Copy of the published article can be obtained by emailing h.o.haugen[AT]ikos.uio.no

as "friendships," and "foreign friends" is a respectful term applied to foreigners who help China further her interests (Brady, 2003).

The social workers had success establishing friendships with people from various African countries. They solicited advice from them on how to improve service provision at Lotus. Examples of services created in dialogue with users included a pan-African soccer team with a local sponsor, a computer space, Chinese and international cultural events, outings to local tourist sites, and free health checks for foreign women. For a few months, the social workers felt that Lotus provided their foreign clients with useful services, and they enjoyed their work.

Nevertheless, the trust the workers at Lotus had built with African residents in Huayuan was fragile, as residents suspected the social workers of helping the Huayuan government surveil the population of foreigners. This suspicion was strengthened on an occasion when the police engaged the social workers as interpreters while performing passport checks in the neighbourhood. Mary encountered the police first; she was asked to help, and the manager of Lotus ordered her to consent. Author A arrived shortly afterward and was also asked to assist. They were both wearing their red social worker suits and standing in plain view. Unavoidably, the centre's foreign clients spotted them and told others that the social workers aided the police. The clients felt betrayed by their "friends" at the Lotus centre, and accused them of harbouring plans to hurt Africans. Realizing the damage this did to their relationships with their clients, the social workers decided not to cooperate with the police to check passports anymore. They managed to mend most of the damaged relationships with clients and continued their work.

The Guangzhou city government promoted the dissemination of professional standards from Hong Kong to integrated family service centres in two main ways. First, the city hired Hong Kong social work scholars to provide each centre with professional guidance. Second, it funded study trips to Hong Kong for social workers from Guangzhou to learn about social service delivery. The social workers from Lotus visited Hong Kong together. Those working with the elderly, youth, and family services found that the Hong Kong model was applicable in Guangzhou. By contrast, those working with foreigners found the differences between Hong Kong and Guangzhou to be immense. The social workers in Hong Kong seemingly could refer foreign clients to other government institutions when needed, whereas such referrals were impossible in mainland China, where foreigners lack the right to access public health, education, and social services. The social workers struggled to see how the operational organization of social work with foreigners in Hong Kong could be applied in the context of 
Postprint. Reference: Niu, D \& Haugen, HØ (2019) The British Journal of Social Work 49 (7), 19321949. Copy of the published article can be obtained by emailing h.o.haugen[AT]ikos.uio.no

mainland China. However, one key idea remained with them after the visit: the principle of confidentiality and respect for the privacy of their clients. In subsequent weeks and months, this would prove crucial to how they handled the growing attention that the centre attracted.

\section{Conflicts, disillusionment, and passive resistance}

The Lotus centre generated a great deal of interest as soon as the services for foreigners were initiated. Journalists from national news outlets frequently reported from the centre in connection with high-level Chinese delegations to African countries, highlighting that interpersonal relations between Africans and Chinese were close and friendly. National politicians showcased Lotus as an example of Sino-African friendship, whereas local politicians mostly were interested in the Lotus centre as a force for social harmony in Huayuan. Scholarly attention to immigration to China had surged by the time the Lotus centre was established, and researchers approached the centre for easy access to informants. The leader of the NGO that operated Lotus welcomed the media and scholarly attention, which reflected positively on the NGO's reputation and could improve future access to funding.

The social workers initially appreciated the coverage of the Lotus centre's work. However, the frequent visits by outsiders were increasingly experienced as disruptive. Furthermore, the visit to Hong Kong had made the social workers aware of the ethical problems of exposing clients without their consent. Clients had told them that they did not want their images published, but the social workers struggled to control where visitors photographed and filmed. Visiting scholars were at times mistaken for social work volunteers by clients, leading to confusion and mistrust. In a discussion about how to manage the situation, the social workers concluded that the attention made their clients insecure. They resolved to protect them against unsolicited attention.

Two incidents during the summer of 2014 challenged the social workers' ability to shield their clients. First, Guangzhou special police forces raided apartments in the Huayuan district in a search for drugs. The local police subsequently requested that the Lotus centre change its name to Lotus Integrated Management Centre and begin checking their clients' passports and reporting undocumented migrants. The relationship between the social workers and the police became strained when the social workers refused to comply. The conflict spilled over into the relations between the social workers, who were working directly with clients, and the management, which prioritized its relationship with the police over the protection of undocumented migrant clients. Second, Ebola broke out in West Africa. The Huayuan government ordered a halt to all social services for foreigners. The immediate 
Postprint. Reference: Niu, D \& Haugen, HØ (2019) The British Journal of Social Work 49 (7), 19321949. Copy of the published article can be obtained by emailing h.o.haugen[AT]ikos.uio.no

concern was that gatherings of Africans could cause an Ebola outbreak in Guangzhou.

Equally important was the belief that services to foreigners attracted them to the area, ultimately resulting in greater social instability. Then no impetus from the central government to sustain social work with foreigners remained, as Zhou Yongkang had been ousted from the Politburo Standing Committee.

During the Ebola outbreak, the local government asked the social workers to go with government representatives to the homes of foreigners to provide information about Ebola and encourage non-Chinese residents to move away from Huayuan. The ultimate aim was to reduce the foreign population. The social workers refused to participate in the information campaign which Author B, when receiving a visit as a foreign resident of Huayuan, indeed experienced as intimidating.

In September 2014, the Guangzhou Association of Social Work carried out a scheduled evaluation of the Lotus centre. In a last attempt to reconcile their desire to provide their clients with services with their determination to protect them from harm, the social workers asked one of the evaluators for her professional opinion. Which action should they take if they realized that one of their clients was an undocumented migrant? The evaluator was clear in her advice: "National interest comes first!" (guojia liyi zhishang). She told them that they had a duty to report all violations of the law, including immigration offenses, to the police. Aware that they were unable to protect their clients and that the Huayuan government now wanted to use Lotus centre as an instrument for controlling the foreign population, the three social workers quit their jobs one by one. Within the space of six months, they left Lotus and abandoned the idea of careers in social work altogether.

\section{Conclusion}

The professional identity of social workers is particularly fluid in China where social work has a short history as a practical discipline, models for delivering social services vary across regions, and academic awareness of foreign theories of social work coexists with strong commitment to finding solutions specific to China. Our analysis has demonstrated the merits of taking an ethnographic approach to understanding how the sweeping changes in the field of Chinese social work play out on the ground. This approach opens up a new line of inquiry in the growing literature on the indigenization of social work in China: How do processes of indigenization and the tensions that these inevitably entail shape the professional identity of social workers? At Lotus, the social workers initially found ways of dealing with contradicting mandates in their everyday practices, but as the casework progressed, they 
Postprint. Reference: Niu, D \& Haugen, HØ (2019) The British Journal of Social Work 49 (7), 19321949. Copy of the published article can be obtained by emailing h.o.haugen[AT]ikos.uio.no

arrived at the conclusion that helping foreign clients and contributing to a harmonious society were mutually exclusive goals. The social workers were subjected to the Chinese discourse of social work as a means to primarily promote a harmonious society, but they were not subjected by it: They eventually refused to follow orders from their superiors in order to protect their clients' interests.

To what extent does the development at Lotus reflect the challenges to professional identity formation in Chinese social work more generally? Social service provision to foreigners was highly politicized from its inception, which brought conflicting loyalties to the fore in particularly stark ways. However, as the literature review above describes, the problems of insufficient training, inadequate supervision, and frustrations over inability to make a positive impact on clients' lives are endemic to social work in China. The expectations that social workers assist authorities in maintaining a harmonious society may compromise their ability to aid and protect Chinese as well as foreign clients. Recent developments in Guangzhou suggest that authorities have attempted to resolve problems of conflicting loyalties by reducing foreign influence on social workers: Mentoring programs with Hong Kong professionals have in part been discontinued, and social workers unaffiliated with Lotus interpret this as a means to suppress notions of social work that are adversary to creating a harmonious society.

China is set on developing social work in ways that makes it uniquely suited to promote national political objectives. At the latest Chinese Communist Party National Congress, President Xi announced that the country will "develop new forms of social governance, and ensure social harmony and stability" (Xinhua, 2017). The social work sector is now a sizable employer with an increasingly visible public presence. During the early stages of expansion, social work was strongly influenced by input from other countries, especially in Asia, and global bodies, such as the International Federation of Social Workers. Interest in foreign experiences seems to decline as China becomes more confident in its capacity to pursue home-grown models. However, Chinese social work scholars must engage with international academic debates to meet ambitious institutional publication targets, and may incorporate ideas from these encounters into their teaching. The professional identity of social workers in China will continue to evolve under multiple sources of influence, and deserves close attention in the future. 
Postprint. Reference: Niu, D \& Haugen, HØ (2019) The British Journal of Social Work 49 (7), 19321949. Copy of the published article can be obtained by emailing h.o.haugen[AT]ikos.uio.no

\section{References}

Adams, K., Hean, S. Sturgis, P. and Clark, J.M. (2006) Investigating the factors influencing professional identity of first-year health and social care students. Learning in Health and Social Care, 5(2):55-68.

Archer, J. (2009) Intersecting feminist theory and ethnography in the context of social work research. Qualitative Social Work, 8(2):143-160.

Bai, J. (2014) What is the role of social work in China? A multi-dimensional analysis. Advances in Social Work, 15(2):495-506.

Ben Shlomo, S., Levy D. and Itzhaky, H. (2012) Development of professional identity among social work students. The Clinical Supervisor, 31(2):240-255.

Brady, A.-M. (2003) Making the foreign serve China: Managing foreigners in the People's Republic. Lanham: Rowman \& Littlefield.

Burke, T.K. (2007) Providing ethics a space on the page: social work and ethnography as a case in point. Qualitative Social Work 6(2):177-195.

Campanini, A., Frost L. and Höjer, S. (2012) Educating the new practitioner: The building of professional identities in European social work. Revista de Asistenta Sociala, 1:33-47.

CCPCC (2006) Zhonggong zhongyang guanyu guojian shehuizhuyi hexie shehui ruogan zhongda wentide jueding (Decisions of the Chinese Communist Party Central Committee on constructing a socialist harmoniuos society). Available at: http://cpc.people.com.cn/GB/64093/64094/4932424.html (accessed 20 January 2016).

Chan, C.K. and Lei J. (2017) Contracting social services in China: The case of the integrated family services centres in Guangzhou. International Social Work 60(6):1343-1357.

de Montigny G.A.J. (1995) Social working: An ethnography of front-line practice. Toronto: University of Toronto Press.

Ferguson, H. (2016) Researchimg social work practice close up: Using ethnographic and mobile methods to understand encounters between social workers, children and families. British Journal of Social Work, 46(1):153-168.

Floersch, J., Longhofer J. and Suskewicz J. (2014) The use of ethnography in social work research. Qualitative Social Work, 13(1):3-7.

Flyvbjerg, B. (2006) Five misunderstandings about case-study research. Qualitative Inquiry, 12(2):219-245.

Gao, J.G. and Yan, M.C. (2015) Social work in the making: The state and social work development in China. International Journal of Social Welfare, 24(1):93-101. 
Postprint. Reference: Niu, D \& Haugen, HØ (2019) The British Journal of Social Work 49 (7), 1932 1949. Copy of the published article can be obtained by emailing h.o.haugen[AT]ikos.uio.no

Gray, M. (2010) Indigenization in a globalizing world: A response to Yunong and Xiong (2008) International Social Work, 53(1):115-127.

Haight, W., Kayama, M. and Korang-Okrah, R. (2014) Ethnography in social work practice and policy. Qualitative Social Work, 13(1):127-143.

Hare, I. (2004) Defining social work for the 21st century: The International Federation of Social Workers' revised definition of social work. International Social Work, 47(3):407-424.

Healy, K. and Meagher, G. (2004) The reprofessionalization of social work: Collaborative approaches for achieving professional recognition. British Journal of Social Work, 34(2):243-260.

IFSW (2012) Statement of Ethical Principles. Available at: http://ifsw.org/policies/statementof-ethical-principles/ (accessed 24 January 2017).

Jiang H., Wang, Y., Chui, E. and Xu, Y. (2017) Professional identity and turnover intentions of social workers in Beijing, China. International Social Work (advance access, doi:10.1177/0020872817712564).

Leung, T.T.F., Yip, N.M., Huang, R., and Wu, Y. (2012) Governmentality and the politicisation of social work in China. British Journal of Social Work, 42(6):1039_ 1059.

Leung, T.T.F. and Tam, C.H.L. (2015) The 'person-centred' rhetoric in socialist China. British Journal of Social Wor, 45(5):1489-1507.

Li, F. (2009) National social work under the multi-cultural background. Heilongjiang Nationalities Series, (25)2:15-19.

Liu, W. (2016) Minban shegong jigou shegong rencai liushi wentide fenxi yu sikao (A study of the brain drain of social workers in private social work organisations), Journal of Graduate School of Chinese Academy of Social Sciences, 38(1):63-68.

Liu, Y., Lam, C.-M. and Yan, M.-C. (2012) A challenged professional identity: the struggles of new social workers in China. China Journal of Social Work, 5(3):189-200.

Ma, D., Qin, K., Shi T. and Gai, K. (2015) Qingshaonian shehui gongzuo xietong fazhan moshi tanxi (The cooperative development model of adolescent social work). Youth \& Adolescence Studies 23(3):51-54.

McDowell, L. (1992) Doing gender: Feminism, feminists and research methods in Human Geography. Transactions of the Institute of British Geographers, 17(4):399-416.

Miehls, D. \& Moffatt, K. (2000) Constructing social work identity based on the reflexive self. British Journal of Social Work, 30(3):339-348. 
Postprint. Reference: Niu, D \& Haugen, HØ (2019) The British Journal of Social Work 49 (7), 19321949. Copy of the published article can be obtained by emailing h.o.haugen[AT]ikos.uio.no

Ministry of Civil Affairs (2018) Minzhengbu bangongting guanyu 2017 niandu shehui gongzuo he zhiyuan fuwu fagui zhengce guihua luoshi qingkuangde tongbao (Notice on the Implementation of Regulations, Policies and Plans for Social Work and Voluntary Services in 2017). Available at: http://www.mca.gov.cn/article/gk/wj/201802/20180215007894.shtml (accessed 6 June 2018).

Ministry of Human Resources/Ministry of Civil Affairs (2006) Guangyu yinfa "shehui gongzuozhe zhiye shuiping pingjia zanxing guiding" he "zhuli shehui gongzuoshi, shehui gongzuoshi zhiye shuiping kaoshi shishi banfa" de tongzhi (Notice on evaluation of the professional level of social workers and examination for junior social workers and social workers). Available at: http://www.mohrss.gov.cn/gkml/xxgk/201407/t20140717_136341.htm (accessed 24 January 2017).

Peng, S.M. (2010) Shanghai shehui gongzuojigoude shengcheng guiji yu fazhan kunjing (The path and development dilemma of Shanghai social work organisations), Journal of Social Sciences, 32(2):54-61.

Rose, G. (1997) Situating knowledges: positionality, reflexivities and other tactics. Progress in Human Geography, 21(3):305-320.

Scanlon, L. (ed.) (2011) "Becoming" a professional: An interdisciplinary analysis of professional learning. Dordrecht: Springer.

Scholar, H., McLaughlin, H., McCaughan, S. and Coleman, A. (2014) Learning to be a social worker in a non-traditional placement. Social Work Education, 33(8):998-1016.

Shu J. (2009) Xuexi Xianggang xianjin jingyan tisheng Guangzhou jingzheng nengli (Study Hong Kong to improve Guangzhou's competitiveness). Available at: http://www.gd.xinhuanet.com/dishi/2009-08/21/content_17464110.htm (accessed 25 January 2017).

Sun, M.N. (2013) Renleixue tianye lunli jiangou youdai wanshan (The construction of anthropological field ethics needs to be improved). In Chinese Social Sciences Today, http://www.csstoday.net/Item/54343.aspx (accessed 5 June 2018).

Thornton, S. and Garrett, K.J. (1995) Ethnography as a bridge to multicultural practice. Journal of Social Work Education 31(1):67-74.

Wang, H. (2014) Guanyu minzu shehui gongzuo xueke fazhande sikao (Thoughts on discipline development of ethnic social work), Journal of Research on Education for Ethnic Minorities 41(4):130-134. 
Postprint. Reference: Niu, D \& Haugen, HØ (2019) The British Journal of Social Work 49 (7), 1932 1949. Copy of the published article can be obtained by emailing h.o.haugen[AT]ikos.uio.no

Wang, S., Sun, Y. and Gu, D. (2015) Shehui gongzuo zonghe nengli (chuji) (Social Work Competence (junior)). Beijing: China Society Press.

White, S.J. (2001) Auto-ethnography as reflexive inquiry: The research act as selfSsrveillance. In: Shaw, I. and Gould, N. (eds.) Qualitative Research in Social Work. London: Sage, pp.100-115.

Witkin, S.L. (1999) Identities and contexts. Social Work 44(4):293-297.

Xinhua (2017) Full text of Xi Jinping's report at 19th CPC National Congress. Available at: http://www.xinhuanet.com/english/special/2017-11/03/c_136725942.htm (accessed 6 June 2018).

Xu, F. (2008) Gated communities and migrant Enclaves: The conundrum for building 'harmonious community/shequ'. Journal of Contemporary China, 17(57):633-651.

$\mathrm{Xu}$, L. and Yue, Z. (2009) Zhou Yongkang zai Guangdong jiu jingji shehui he weiwen jinxing diaoyan (Zhou Yongkang's investigation on economic and social stability in Guangdong). Available at: http://news.sina.com.cn/c/2009-0904/135318581611.shtml (accessed 25 January 2017).

Yan, L. (2010) Guangzhou shiwei shuji zhangguangning: Yi Xinjiapo wei xuexi zhuigan xin biaogan (Secretary of the Guangzhou Municipal Party Committee: Visiting Singapore to learn). Available at: http://politics.people.com.cn/GB/14562/11823329.html (accessed 25 January 2017).

Yan, M.C. and Cheng, S.1. (2009) Searching for Chinese characteristics: a tentative empirical examination. China Journal of Social Work 2(1):5-19.

Yan, M. C. and Tsang, A. K. T. (2008) 'Re-envisioning indigenization: When bentuhuade and bentude social work intersect in China', in Gray, M., Coates, J. and Yellow Bird, M. (eds.) Indigenous Social Work Around the World: Towards Culturally Relevant Education and Practice, London, Ashgate, pp. 191-202.

Zhao, F., Fu, F. and Yang, B. (2017) Social work value system in mainland China: Construction of a scale and value commitment assessment. International Social Work (advance access, doi:10.1177/0020872816682582).

Zhao, S. and Yao, L. (2015) Minzu shehui gongzuo gainian bianxi (Social work with ethnic minorities). Heilongjiang National Series 31(5):29-33. 